\title{
Mechanism of the decarboxylative rearrangement of $\alpha$-(carbonyl)cyclopropane carboxylic acids to 2-substituted-4,5-dihydrofurans
}

\author{
Edwin Jahngen*, Jeffrey Mallett, Roger O’Connor, and Sarah Fischer \\ Department of Chemistry, University of Massachusetts Lowell, Lowell, MA -01854- \\ E-mail: Edwin_Jahngen@uml.edu
}

Dedicated to Professor Berhanu Abegaz on the occasion of his $60^{\text {th }}$ birthday

\begin{abstract}
Previously we described the thermal decarboxylation of 1-(cyclopropylcarbonyl) cyclopropane carboxylic acid at $120^{\circ} \mathrm{C}$ yielded 2-cyclopropyl-4,5-dihydrofuran instead of the expected dicyclopropyl ketone. The proposed mechanism proceeded through an initial ring opening of the 1,2-disubstitued cyclopropyl moiety leading to an $\alpha$-allyl- $\beta$-keto acid system, specifically in this case $\alpha$-(cyclopropylcarbonyl)-3-butenoic acid. In this paper we demonstrate that an $\alpha$ (carbonyl)-3-butenoic acid when thermally decarboxylated rearranges to the substituted 4,5dihydrofuran. Additionally, it was demonstrated that the decarboxylation and rearrangement are simultaneous and not a stepwise decarboxylation followed by rearrangement and ring closure.
\end{abstract}

Keywords: 2-Substituted-4,5-dihydro furans, decarboxylative rearrangement, dianions of carboxylic acids, $\alpha$-(carbonyl)-3-butenoic acid

\section{Introduction}

In a previous report studying the reactions of the dianion of cyclopropane carboxylic acid it was observed that at higher temperatures the acid dimerized to $\alpha$-[cyclopropylcarbonyl] cyclopropane carboxylic acid. This $\beta$-keto acid was found to undergo a facile decarboxylation at $120^{\circ} \mathrm{C}$, yielding not the expected dicyclopropyl ketone, but rather 2-cyclopropyl-4,5dihydrofuran. At that time we proposed a mechanism in which the initial step of the sequence was a ring opening of the $\alpha$-[cyclopropylcarbonyl] cyclopropane carboxylic acid to $\alpha$ (cyclopropylcarbonyl)-3-butenoic acid. This would be followed by decarboxylation and ring closure to the 2-cyclopropyl-4,5-dihydrofuran. These steps are summarized in Scheme 1. ${ }^{1}$ 


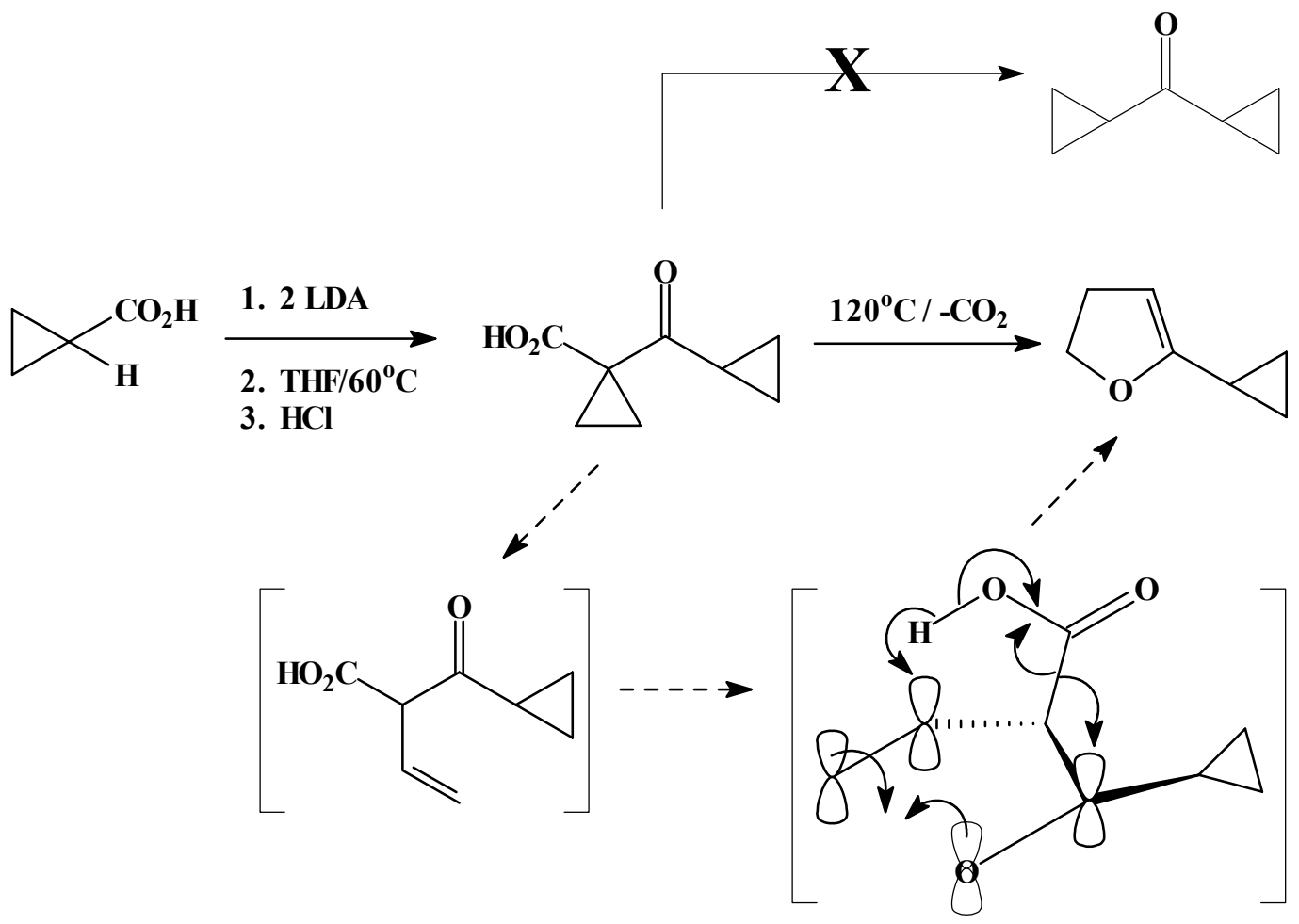

\section{Scheme 1}

A well documented chemistry of cyclopropyl rings adjacent to $\pi$ systems is the ring opening of the cyclopropyl moiety and rearrangement to an extended cyclic system. This chemistry has been induced thermally ${ }^{2}$, photochemically ${ }^{3}$ and with the use of catalysts ${ }^{4}$. Depending on the conditions, the mechanism of these reactions may range from formal ionic charges ${ }^{5}$, through diradical $^{6}$ to concerted ${ }^{7},([1,3]$ sigmatropic rearrangement).

While the rearrangement of vinylcyclopropanes to cyclopentenes ${ }^{2,3}$ and cyclopropylimines to 4,5-dihydropyrroles ${ }^{8}$ have found utility in synthesis, it is the rearrangement of cyclopropyl ketones to 4,5-dihydrofurans that has interested us ${ }^{6 c}$. An early study carried out by McGreer and McKinley concluded that both the photochemically and thermally induced formation of 4,5dihydrofurans proceeded through a diradical species $^{6 c}$. The diradical mechanism was demonstrated through the regio-specificity of the ring expansion that lead to the dihydrofuran, the stereochemistry of the reaction lead to isomerization of stereochemical centers. This is a phenomenon of ring opening prior to ring closure is shared by the rearrangements of vinylcyclopropane and cyclopropylimines to the corresponding cyclopentenes and dihydropyrroles respectively ${ }^{2,3,8}$. It has been shown that the stereochemistry of the ring expansion could be controlled by the addition of $\mathrm{Al}_{2} \mathrm{O}_{3}$, which presumably acts as a template for the reaction ${ }^{3}$.

Another interesting reaction is the ring of opening cyclopropane carboxylic acid to the $\beta, \gamma-$ unsaturated acid prior to decarboxylation ${ }^{9}$. In that study it was also demonstrated that the thermal 
decarboxylation of cyclopropylacetic acids also involves a cyclic transition state, however, without the initial ring opening step. The decarboxylation of $\alpha, \beta$-unsaturated acids were not considered because they are considerably more difficult to decarboxylate, usually requiring catalytic intervention ${ }^{8}$. It was demonstrated that cyclopropane carboxylic acid decarboxylated to propene rather than cyclopropane and this occured through the initial ring opening leading to a diradical that is facilitated and stabilized by the carboxyl moiety. A 1,2 shift of the $\beta$ hydrogen then leads to either directly to but-3-enoic acid or the conjugated crotonic acid which are in equilibrium through a 1,3-hydrogen shift. Ultimately the decarboxylation occurs through a cyclic transition state from the but-3-enoic acid, reminiscent of cyclopropylacetic acids ${ }^{9}$. Evidence for this is the fact but-3-enoic decarboxylates at $290^{\circ} \mathrm{C}$, while crotonic acid is stable up to $520^{\circ} \mathrm{C}$ and the cyclopropane carboxylic acid appears to loose $\mathrm{CO}_{2}$ at $340^{\circ} \mathrm{C}$. This is shown in scheme 2 .

a]

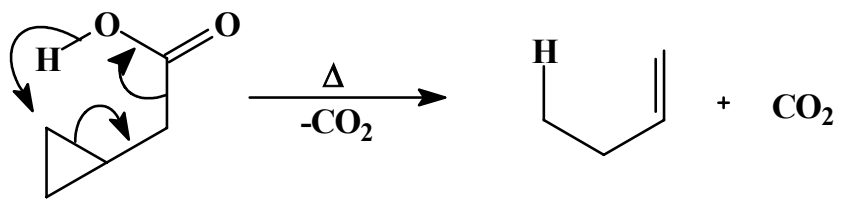

b]

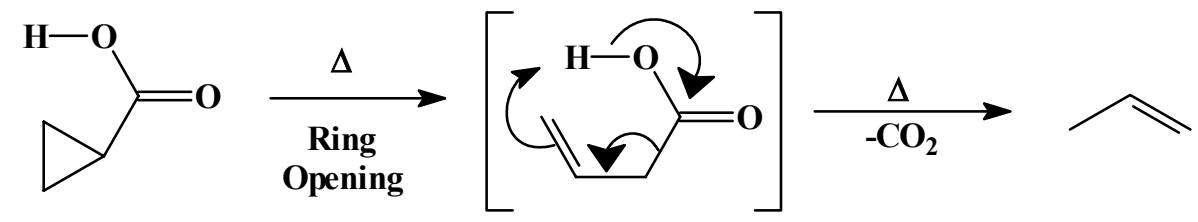

\section{Scheme 2}

In this paper we have synthesized a number of compounds that may represent intermediates along the pathway of the observed decarboxylative rearrangement of $\alpha$-[cyclopropylcarbonyl] cyclopropane carboxylic acid. In addition to a number of $\alpha$-(carbonyl) cyclopropane carboxylic acids to demonstrate the generality of the reaction, we have also synthesized the corresponding putative intermediate, $\beta, \gamma$-unsaturated ketones and the $\alpha$-allyl- $\beta$-keto acids.

\section{Results and Discussion}

It was thought, based on the literature, that the observed rearrangement ${ }^{1}$ could occur through either an initial ring opening of the central cyclopropane ${ }^{9}$ in $\alpha$-(cyclpropylketo) cyclopropane carboxylic acid, followed either by a simultaneous decarboxylation and cyclization to the 4,5dihydrofuran, or a stepwise decarboxylation to the $\beta, \gamma$-unsaturated ketone and subsequent ring closure to the 4,5-dihydrofuran. While there is a possibility that the entire decarboxylationrearrangement occurs simultanelously, the possibility of an initial decarboxylation of the $\beta$-keto 
acid leaving an intact cyclopropyl ring was discounted since our previous studies on the decarboxylation of $\alpha$-[cyclopropylcarbonyl] cyclopropane carboxylic acid or $\alpha$ [phenylcarbonyl]cyclopropane carboxylic acid resulted in no isolation of dicyclopropyl ketone and only $8 \%$ of cyclopropyl phenyl ketone ${ }^{1}$. Both dicyclopropyl and cyclopropyl phenyl ketone were thermally stable under the conditions used for the decarboxylative rearrangement presented above. In fact the rearrangement of a cyclopropyl ketone to a 4,5-dihydrofuran, could be induced in the presence of strong acid as previously demonstrated ${ }^{5 \mathrm{a}}$.

To examine the generality of the decarboxylative rearrangement a number of $\alpha$-(carbonyl) cyclopropane carboxylic acids were synthesized. The synthetic protocol was based upon the previously reported formation of $\beta$-keto acids from the $\alpha$ anions of carboxylic acids ${ }^{10}$. In this case the dianion of cyclopropane carboxylic acid was formed at $-78^{\circ} \mathrm{C}$ warmed to $0^{\circ} \mathrm{C}$ and reacted with an acid chloride yielding the desired $\beta$-keto acid. Careful isolation of the $\beta$-keto acid was required to prevent decarboxylation during workup. To that end the reaction mixture was poured over ice, extracted with ether and carefully acidified with $0.1 \mathrm{~N} \mathrm{HCl}$. While some self condensation of the cyclopropane carboxylic acid was observed, the majority of the product was the desired $\beta$-keto acid. On two occasions we attempted to affect the condensation using an ester as the electrophile. In these cases we found that at $0^{\circ} \mathrm{C}$, the esters appeared to react very slowly, while at the slightly elevated temperature of $20^{\circ} \mathrm{C}$, significant amounts of the diaddition product of the $\alpha$-anion of the cyclopropane carboxylic acid were formed ${ }^{11}$. All of the products were decarboxylated neat at $120^{\circ} \mathrm{C}$ and yielded the respective 4,5-dihydrofuran, [Scheme \#3].

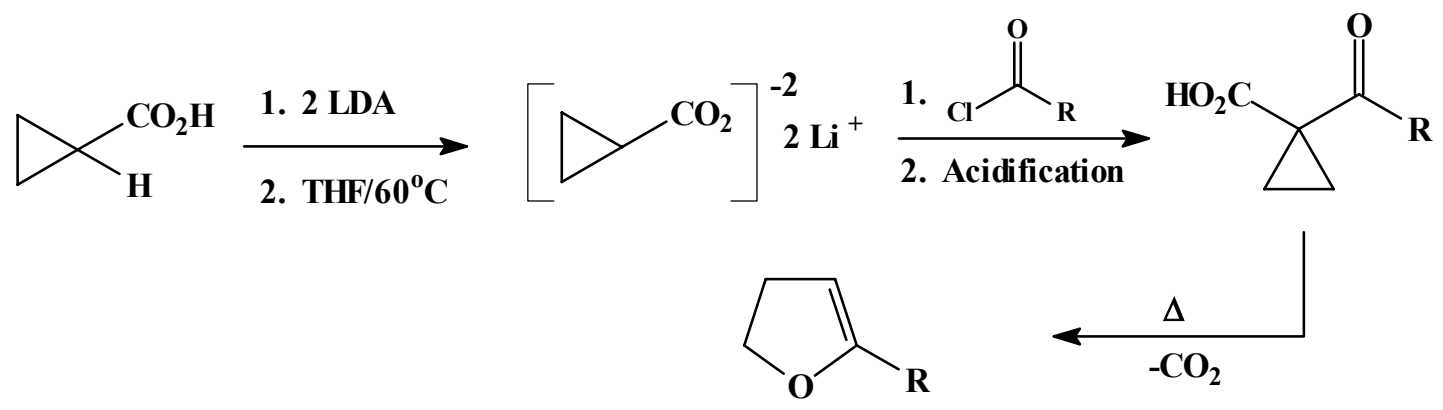

\section{Scheme 3}

Only in the case of the case of $\alpha$-(phenylcarbonyl) cyclopropane carboxylic acid was any cyclopropyl phenyl ketone observed, (8\%), however, no 2-propenyl phenyl ketone was found. These data are significant since it would appear that prior decarboxylation of $\alpha$-(phenylcarbonyl) cyclopropane carboxylic acid prevented the rearrangement to the 4,5-dihydrofuran as mentioned above. These results are summarized in Table 1. When cyclopropyl phenyl ketone, (a possible intermediate to the 4,5-dihydro furan), was subjected to the conditions used for the decarboxylation of the $\alpha$-(phenylcarbonyl) cyclopropane carboxylic acid, no change in the 
starting material was observed. These data suggest that in the presence of the phenyl moiety, the energy barrier is lowered for the simple decarboxylation prior to cyclopropyl ring opening.

To demonstrate the general participation of the cyclopropane ring in the rearrangement, we synthesized a number of $\beta$-keto acid compounds that did not have the central cyclopropane ring; however, they were disubstituted at the $\alpha$-position. The dianions of carboxylic acids were formed as previously described and treated with acid chlorides ${ }^{10}$. Careful acidification of the product led to the desired crystalline $\beta$-keto acids (Scheme 4).

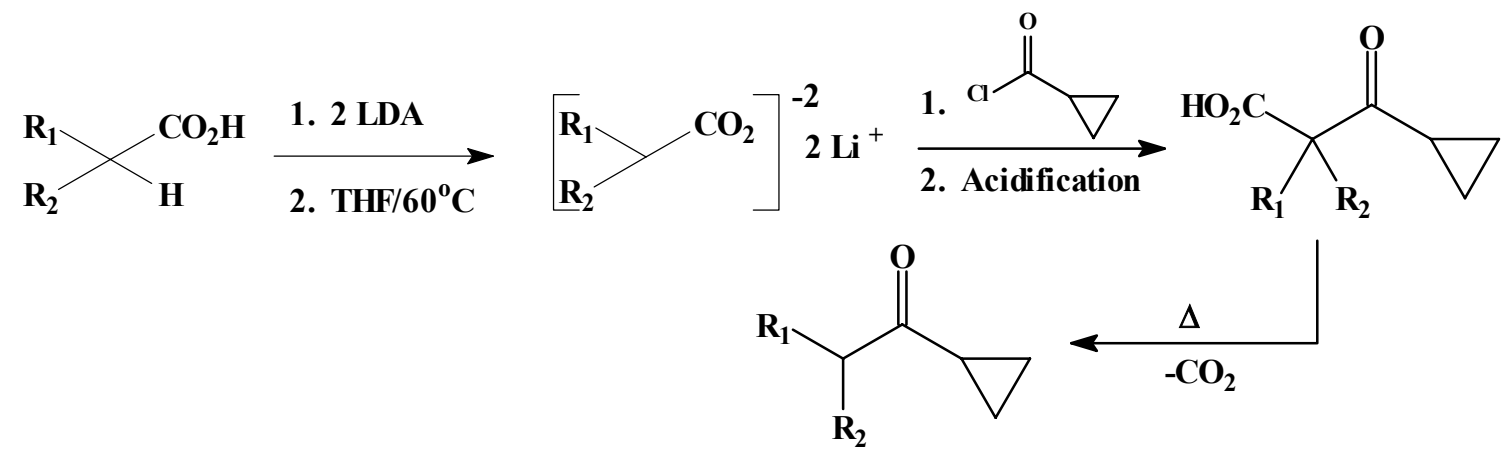

\section{Scheme 4}

While the $\alpha, \alpha$-disubstituted $\beta$-keto acids could be isolated, and subsequently decarboxylated, mono substitution at the $\alpha$-position lead only to the isolation of the appropriate ketone. Upon work up of the condensation reactions intractable oils were formed and any attempt to purify the presumed $\beta$-keto acid led to loss of $\mathrm{CO}_{2}$ and the formation of the appropriate ketone. In the case of the $\beta$-keto acids formed from the dianions of phenyl acetic acid and cyclohexane carbonyl chloride it was shown that the diisopropylammonium salt of the $\beta$-keto acid could be isolated. Attempt to acidify the salt to the free acid would result in decarboxylation upon work up to the ketone $^{10 \mathrm{~b}}$. These reactions and those containing a central cyclopropane ring are summarized in Table 1.

These data suggest that the $\alpha$-(carbonyl) cyclopane carboxylic acid or its ring opened intermediate are critical to the rearrangement. If the cyclopropyl ring is located $\gamma$ to the acid and $\alpha$ to the ketone such as the last three examples in Table 1 the reaction observed is simply the expected decarboxylation to the ketone. However, in $\beta$-keto esters such as ethyl 3-cyclopropyl-3oxopropanoate the literature shows that during pyrolysis thermal decarboxylation leads to 2cyclopentenones $^{12}$. This only occurs if there is only mono-substitution in the $\alpha$-position of a $\beta$ keto acid, if it is $\alpha, \alpha$-disubstituted only the ketone is observed. This is shown in Scheme \#5. While the mechanism of this decarboxylative rearrangement of an ester, which occurs between $500^{\circ} \mathrm{C}$ and $600^{\circ} \mathrm{C}$ is unrelated to our reported decarboxylative rearrangement of the $\beta$-keto acid at $120^{\circ} \mathrm{C}$ rearrangement to the 4,5 -dihydrofurans, it points to the critical involvement of the 1,1 diacyl substituted cyclopropyl system. 
Table 1. Decarboxylation reactions of various $\beta$-keto acids

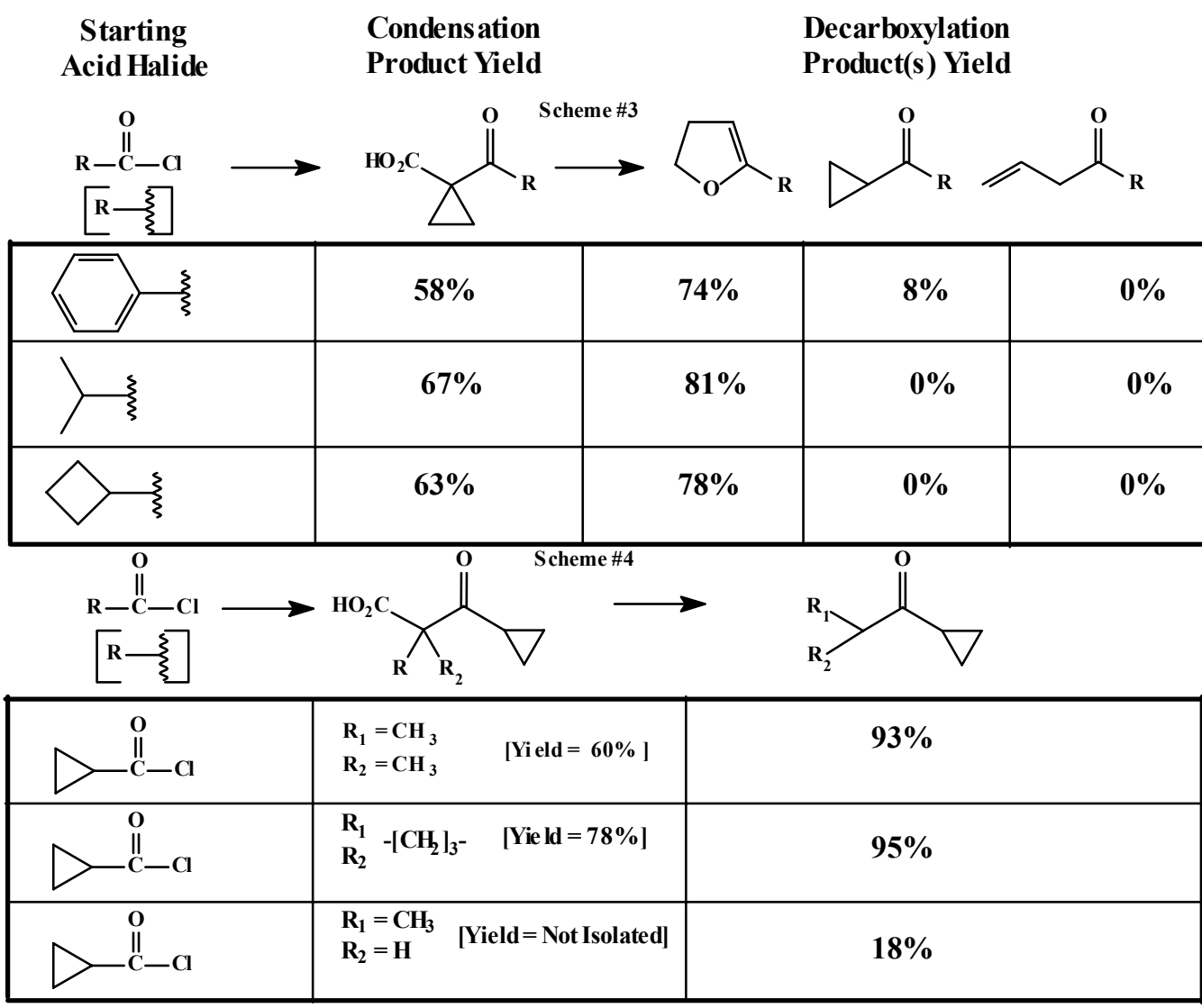<smiles>CCOC(=O)C(C)C(=O)C1CC1</smiles>

\section{Scheme 5}

It has been shown that during the decarboxylation of a cyclopropane carboxylic acid, ring opening precedes the loss of $\mathrm{CO}_{2}$ albeit at a high temperature ${ }^{7 b, c}$. In the case of a $\alpha$-(carbonyl) cyclopropane carboxylic acid the ring opening would be especially facile because the cyclopropyl ring is adjacent to two carbonyl system. The efficacy of the proposed 1,3-bond cleavage would be due to the considerable stabilization of the radical in the 1 position. The lack of stabilizing substitutents on the 3-position may facilitate the 1,2-hydrogen shift leading to either the 2-(carbonyl)-2-butenoic acid or the 2-(carbonyl)-3-butenoic acid. The next step of the rearrangement could either be a sequential decarboxylation to form the $\alpha, \beta$ - or $\beta, \gamma$-unsaturated ketone, and subsequent ring closure to the 4,5-dihydrofuran. Alternatively, a simultaneous 
decarboxylation and concerted or unsymmetrically concerted ring closure, could lead to the 4,5dihydrofuran (Scheme 6).<smiles>[R]C(=O)C1(C(=O)O)CC1</smiles>

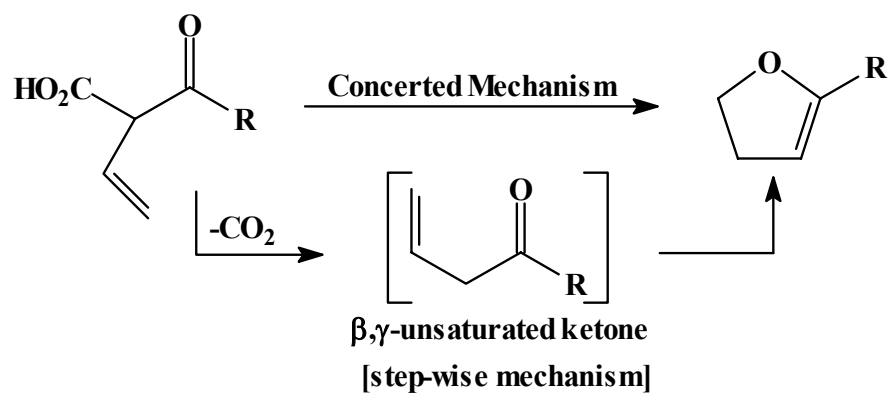

\section{Scheme 6}

To examine these possibilities a series of allyl ketones and $\alpha$-allyl- $\beta$-keto acids were synthesized and examined as possible intermediates for the step-wise ring opened rearrangement.

The synthesis of the allyl ketones was carried out using Lewis acid promoted Barbier-type reactions of nitriles ${ }^{13}$. Using $\mathrm{Zn}^{\circ}$ in place of $\mathrm{Mg}^{\circ}$ and an allyl bromide to form the nucleophile the allyl ketones were synthesized in yields ranging from $60 \%$ to $85 \%$ (Scheme 7 ).

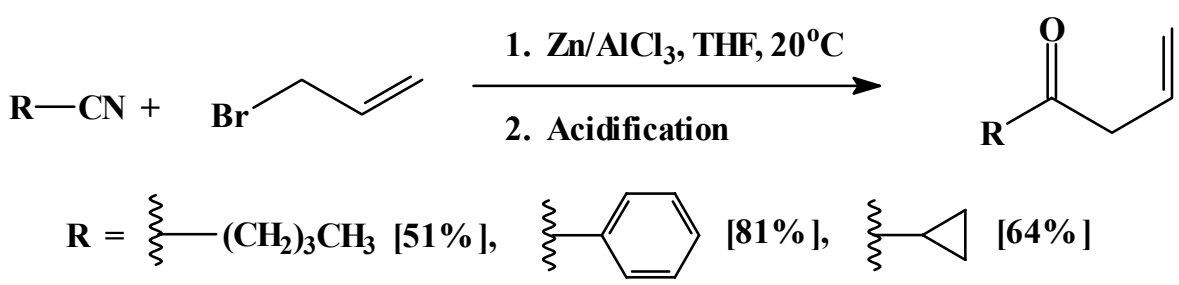

\section{Scheme 7}

The allyl ketones were then subjected to high temperatures to attempt thermal rearrangement. At temperatures up to $200^{\circ} \mathrm{C}$ no rearrangement of the allyl ketones to 4,5-dihydrofurans was observed after 300 minutes. Substitution of a cyclopropyl moiety for the allyl group on the ketone, specifically, methyl-, cyclopropy- and phenyl cyclopropyl ketones, yielded none of the rearrangement product, the 4,5-dihydrofuran. These data suggest that decarboxylation does not precede the rearrangement by leading to an allyl ketone intermediate. 


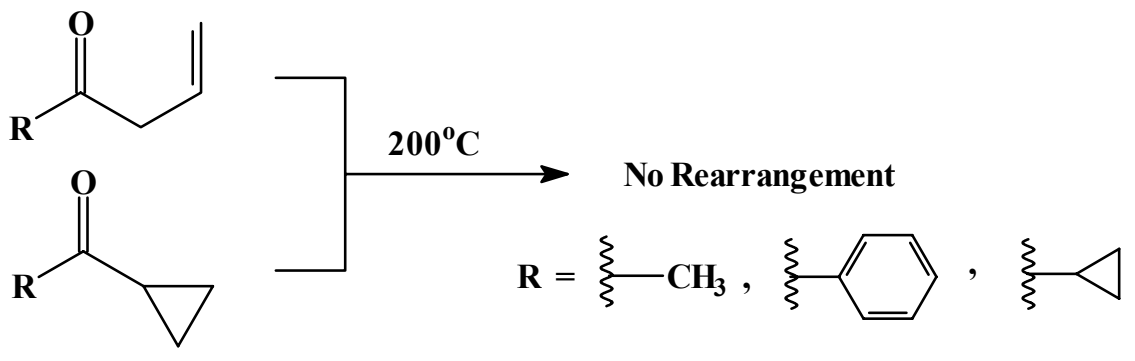

\section{Scheme 8}

To examine the alternative mechanism, the synchronous decarboxylation-rearrangement a series of $\alpha$-allyl- $\beta$-keto acids was synthesized. Forming the dianion of a $\beta, \gamma$-unsaturated carboxylic acid has been shown in the past to yield alkylation at the $\alpha$-position ${ }^{14}$. Using the previously described method to form $\beta$-keto acids from the dianion of carboxylic acids and acid halides we were able to synthesize the desired $\alpha$-allyl $\beta$-keto acids shown in scheme 9 .
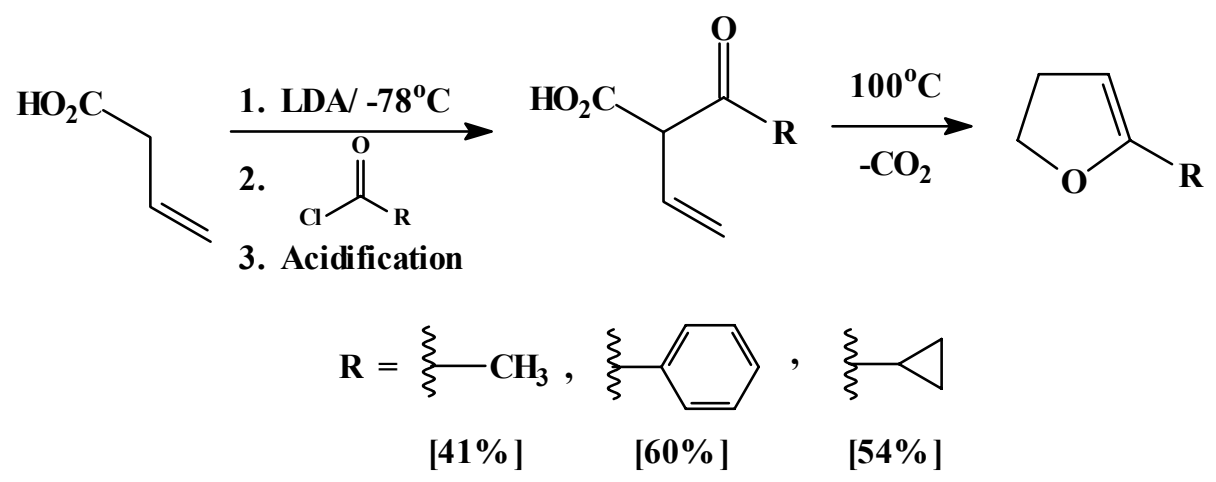

\section{Scheme 9}

The $\alpha$-allyl- $\beta$-keto acids were found to readily undergo decarboxylation at $100^{\circ} \mathrm{C}$ and in all cases led to the corresponding 2-dubstituted-4,5-dihydro furans, with no evidence of the ketones, except for $\alpha$-(phenylcarbonyl)-3-butenoic acid which gave $7 \%$ of phenyl allyl ketone. To examine the need for the presence of the carboxylic acid, methyl esters of these $\alpha$-allyl- $\beta$-keto acids were made by methylation with diazomethane. These compounds were relatively stable up to $150^{\circ} \mathrm{C}$ for 2 hours yielding some decomposition, unreacted starting material and no evidence of 4,5-dihydro furans based on nmr. These data suggest that the decarboxylation of the $\alpha$-allyl- $\beta$ keto acid is synchronous with the rearrangement to the 2-substituted-4,5-dihydrofuran. Interestingly, the acid catalyzed hydrolysis of the esters in ethanol/water with tosic acid yielded the ketone as the major product with only a trace amount of the 2-substituted-4,5-dihydrofuran. These data are shown in Table 2. 
Table 2. Decarboxylative rearrangement of a-(carbonyl)-3-butenoic acids and esters

Starting

Acid Halide
Condensation

Product Yield
Decarboxylation

Product(s) Yield

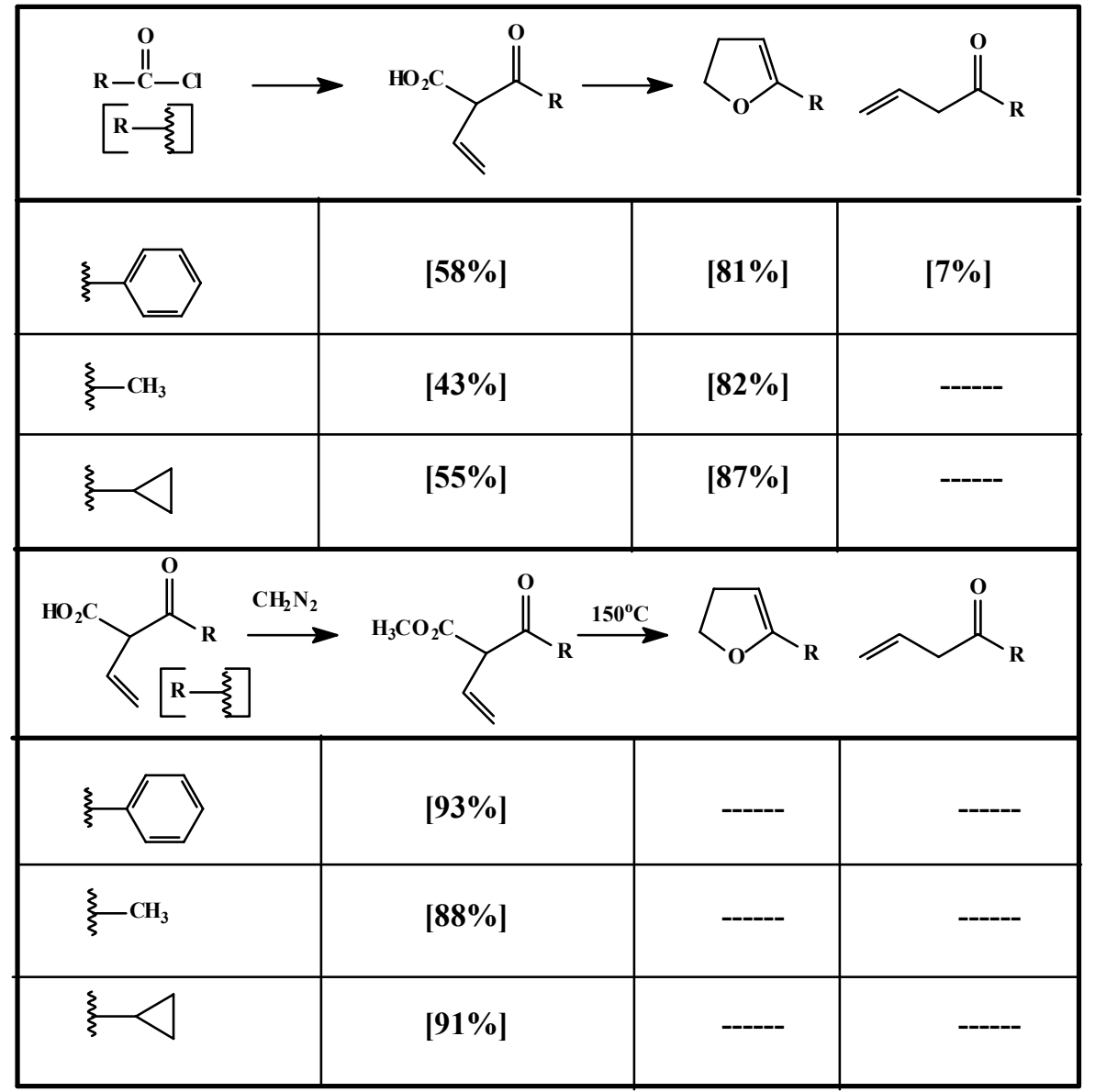

According to the work of Husigen ${ }^{15}$, if the decarboxylation-rearrangement is concerted or unsymmertically concerted it could be reasoned that there should be little solvent effect on either the rate of the reaction or the product composition if the transition state has little polar character. However, if there is ionic character to the transition state or if an intermediate is involved in the reaction, stabilization of the transition state and intermediate could result in rate increases as high as $10^{7}$. Using the Snyder polarity index as a guide ${ }^{16}$ a solution of $\alpha$-(phenylcarbonyl)-3-butenoic acid in either cyclohexane, toluene, dichloro ethylene,1,4-dioxane, acetonitrile, DMF or DMSO, all aprotic systems and heated to $120^{\circ} \mathrm{C}$ in low pressure vessels. At specific time points a sample was removed, treated with diazomethane to esterify any acid present and the ratios of ester, furan and ketone, were analyzed by gas chromatography. The results are summarized in Table 3 . As the polarity of the solvent increased the relative rate of the reaction was also shown to increase. The neat $\alpha$-(phenylcarbonyl)-3-butenoic acid was found to decarboxylate and rearrange to the 2phenyl-4,5-dihydrofuran at a rate similar to the rate in cyclohexane. The relative rates were 1.0 
for the neat material and 1.2 for the cyclohexane solution respectively. This would be expected since cyclohexane has a polarity of 0 in the Snyder index. As the polarity of the solvent the relative rate of the reaction increased with the fastest rate being observed in DMF with a Snyder index of 7.3. However it should be noted that the increase in rate is only 31 times faster in the DMF than in the cyclohexane, suggesting that the reaction is essentially concerted perhaps with some unsymmertical character.

To relate the decarboxylation-rearrangement of $\alpha$-(phenylcarbonyl)-3-butenoic acid to the decarboxylation-rearrangement of the analogous $\alpha$-(phenylcarbonyl) cyclopropane carboxylic acid, the same solvent study was performed. It was observed that while the overall rate for the $\alpha$-(phenylcarbonyl) cyclopropane carboxylic acid was slower than the $\alpha$-(phenylcarbonyl)-3butenoic acid, the same overall effect was noted suggesting that the two reactions and rearrangements were occurring through a similar process, with the initial ring opening of the cyclopropyl ring radical rather than ionic character (Table 3).

Table 3. Effect of solvent polarity on the solution decarboxylative rearrangement of a(phenylcarbonyl) cyclopropane carboxylic acid

\begin{tabular}{cccc}
\hline Solvent $[10 \mathrm{mM}]$ & $\begin{array}{c}\text { Snyder } \\
\text { Index }\end{array}$ & $\begin{array}{c}\text { Relative Rate } \\
\text { (2henylcarbonyl)- } \\
\text { 3-butenoic acid }\end{array}$ & $\begin{array}{c}\text { Relative Rate } \\
\text { a(phenylcarbonyl)cyclopropane } \\
\text { carboxylic acid }\end{array}$ \\
\hline Neat & & 1 & 1 \\
Cyclohexane & 0 & 1.2 & 1.1 \\
Toluene & 2.3 & 2.4 & 1.9 \\
Dichloroethylene & 3.7 & 6.7 & 5.3 \\
1,4-dioxane & 4.8 & 11.3 & 9.8 \\
Acetonitrile & 6.2 & 19.5 & 17.3 \\
DMF & 7.3 & 314 & 27.2 \\
\hline
\end{tabular}

It has therefore been concluded that the previously described decarboxylation and rearrangement of $\alpha$-(cycloproplycarbonyl) cyclopropane carboxylic acid to 2-cyclopropyl-4,5dihydrofuran proceeds by initial ring opening of the disubstituted cyclopropane to an $\alpha$ (carbonyl)-3-butenoic acid. This is followed by a concerted or unsymmetrically concerted decarboxylation and rearrangement of the $\alpha$-(carbonyl)-3-butenoic acid to the observed 2cyclopropyl-4,5-dihydrofuran. This conclusion is supported by the fact that either both the $\alpha$ (cycloproplycarbonyl) cyclopropane carboxylic acid, and analogues and the $\alpha$ (cyclopropylcarbonyl)-3-butenoic acid, and analogues undergo thermal decarboxylative rearrangement to the same products at similar rates. This methodology appears to represent a general method to substituted 4,5-dihydrofurans. 


\section{Experimental Section}

General Procedures. All melting points were determined on a Thomas-Hoover apparatus and were uncorrected. All reactions involving LDA or anhydrous conditions were run under argon in glassware that was dried at $160^{\circ} \mathrm{C}$. Tetrahydrofuran was distilled from sodium, benzophenone being used as an indicator. All starting materials and reagents were purchased from Acros or Sigma-Aldrich. Microanalysis was performed by Galbraith Laboratories. Infrared spectra were obtained on a Perkin Elmer 1760 FT-IR, and Proton NMR were determined on a Bruker 250 FTNMR. Gas chromatography was performed on an HP-5890 Series II fitted with a flame ionization detector, auto injector, [HP-6890] and a $0.25 \mathrm{~mm}$ x $30 \mathrm{~m}$ HP-PLOT $\mathrm{Al}_{2} \mathrm{O}_{3}$ "S" capillary column.

\section{Preparation of lithium $\alpha$-lithiocyclopropanecarboxylate}

A $100 \mathrm{~mL}$ three necked flask was fitted with a magnetic stirrer, serum cap, argon inlet and addition funnel containing $10 \mathrm{mmol}$ of cyclopropanecarboxylic acid, $(0.86 \mathrm{~g})$, in $5 \mathrm{~mL}$ of dry THF. The flsak was charged with $25 \mathrm{~mL}$ of dry THF and $20 \mathrm{mmol},(2.04 \mathrm{~g})$, of diisopropyl amine and cooled to $-20^{\circ} \mathrm{C}$. To the stirred solution was injected $20 \mathrm{mmol},(12.5 \mathrm{~mL})$, of $1.6 \mathrm{M} \mathrm{n}$ BuLi in Hexanes. The resulting LDA solution was then stirred an additional one hour at $-20^{\circ} \mathrm{C}$ prior to the addition of the appropriate acid chloride.

\section{General preparation of $\alpha$-(carbonyl)cyclopropanecarboxylic acid}

To the prepared solution of Lithium $\alpha$-Lithiocyclopropanecarboxylate the acid chloride (10 mmol) was added in $10 \mathrm{~mL}$ of dry $\mathrm{THF}$ at $-70^{\circ} \mathrm{C}$ and the mixture was stirred an additional 30 minutes. The reaction mixture was added to $20 \mathrm{~mL}$ of $2 \mathrm{M} \mathrm{HCl},(40 \mathrm{mmol})$, and $50 \mathrm{~g}$ of ice. The cloudy solution was washed three times with $30 \mathrm{~mL}$ of $\mathrm{CH}_{2} \mathrm{Cl}_{2}$. The combined organic layers were dried over $\mathrm{MgSO}_{4}$, filtered and the solvent evaporated under reduced pressure. All operations were kept at $0^{\circ} \mathrm{C}$. Upon triturating with cold pentane crystalline $\alpha$ (carbonyl)cyclopropanecarboxylic acids were obtained.

$\alpha$-(Cyclopropylcarbonyl)cyclopropanecarboxylic acid. The crude solid, $0.61 \mathrm{~g}$, (78\%), was recrystallized from a 1:2 pentane-ether to yield $0.52 \mathrm{~g}$, $(64 \%)$ of a solid $\left(\mathrm{mp} 85-87^{\circ} \mathrm{C}\right)$. IR $\left(\mathrm{CCl}_{4}\right)$ 3400-2450, (br), 1690, 1440, 1230, $925 \mathrm{~cm}^{-1} ;{ }^{1} \mathrm{H}$ NMR $\left(\mathrm{CDCl}_{3}\right) \delta 12.7$ (br, 1H), 2.0-1.6 (m, 4 $\mathrm{H})$, 1.7-1.0 (m, 5H). Elemental Analysis, Calculated for $\mathrm{C}_{8} \mathrm{H}_{10} \mathrm{O}_{3}: \mathrm{C}$ 62.34; H, 6.49. Found: $\mathrm{C}$, $62.62 ; \mathrm{H}, 6.53$.

$\alpha$-(Phenylcarbonyl)cyclopropanecarboxylic acid. The crude solid was recrystallized from a 1:4 acetone-ether to yield $0.68 \mathrm{~g},(35.8 \%)$ of a solid $\left(\mathrm{dec},\left(-\mathrm{CO}_{2}\right)>100^{\circ} \mathrm{C}\right)$. IR $\left(\mathrm{CCl}_{4}\right) 3400-2500$, (br), 1695, 1600, 1455, 1425, 1330, 1275, $1010 \mathrm{~cm}^{-1}$; ${ }^{1} \mathrm{H}$ NMR $\left(\mathrm{CDCl}_{3}\right) \delta 12.8(\mathrm{br}, 1 \mathrm{H}), 7.9(\mathrm{~m}$, $2 \mathrm{H}), 7.6(\mathrm{~m}, 3 \mathrm{H}), 1.6\left(\mathrm{~A}_{2} \mathrm{~B}_{2}, 4 \mathrm{H}\right)$. Elemental Analysis, Calculated for $\mathrm{C}_{11} \mathrm{H}_{10} \mathrm{O}_{3}$ : C 69.47; $\mathrm{H}$, 5.26. Found: $\mathrm{C}, 69.73 ; \mathrm{H}, 5.61$.

$\alpha$-(Isopropylcarbonyl)cyclopropanecarboxylic acid. The crude solid, $1.06 \mathrm{~g}$, (68\%), was recrystallized from a 1:1 pentane-ether to yield $0.84 \mathrm{~g},(54 \%)$ of an oil that decomposed upon attempted distillation $\left(\operatorname{dec}\left(-\mathrm{CO}_{2}\right)>90^{\circ} \mathrm{C}\right)$. IR $\left(\mathrm{CCl}_{4}\right) 3400-2500$, (br), 1696, 1480, 1360, 1200, 
1150, $960 \mathrm{~cm}^{-1} ;{ }^{1} \mathrm{H}$ NMR $\left(\mathrm{CDCl}_{3}\right) \delta 12.3$ (br, 1H), 2.6 (heptet, $\left.1 \mathrm{H}\right), 2.0-1.6(\mathrm{~m}, 4 \mathrm{H}), 1.4(\mathrm{~d}$, $6 \mathrm{H})$. Elemental Analysis, Calculated for $\mathrm{C}_{8} \mathrm{H}_{12} \mathrm{O}_{3}$ : C 61.53; H, 7.69. Found: C, 62.22; H, 7.12. $\alpha$-(Methylcarbonyl)cyclopropanecarboxylic acid. The crude solid, $0.66 \mathrm{~g},(52 \%)$, was recrystallized from a 1pentane to yield $0.42 \mathrm{~g},(33 \%)$ of a semi-solid $\left(\mathrm{mp} 53-57^{\circ} \mathrm{C}\right.$, dec $\left(-\mathrm{CO}_{2}\right)>$ $\left.90^{\circ} \mathrm{C}\right)$. IR $\left(\mathrm{CCl}_{4}\right)$ 3400-2450, (br), 1685, 1410, 1190, 1095, 1020, 970, $900 \mathrm{~cm}^{-1}$; ${ }^{1} \mathrm{H} \mathrm{NMR}$ $\left(\mathrm{CDCl}_{3}\right) \delta 12.9(\mathrm{br}, 1 \mathrm{H}), 2.17(\mathrm{~s}, 3 \mathrm{H}), 2.0-1.6(\mathrm{~m}, 4 \mathrm{H})$. Elemental Analysis, Calculated for $\mathrm{C}_{6} \mathrm{H}_{8} \mathrm{O}_{3}$ : C 56.34; $\mathrm{H}, 6.25$. Found: C, 56.57; H, 6.13.

\section{Preparation of lithium $\alpha$-lithio carboxylates}

A $100 \mathrm{~mL}$ three necked flask was fitted with a magnetic stirrer, serum cap, argon inlet and addition funnel containing $10 \mathrm{mmol}$ of the appropriate carboxylic acid, in $5 \mathrm{~mL}$ of dry THF. The flask was charged with $25 \mathrm{~mL}$ of dry THF and $20 \mathrm{mmol}$, $(2.04 \mathrm{~g})$, of diisopropyl amine and cooled to $-20^{\circ} \mathrm{C}$. To the stirred solution was injected $20 \mathrm{mmol},(12.5 \mathrm{~mL})$, of $1.6 \mathrm{M} n$-BuLi in Hexanes. The resulting LDA solution was then heated to $50^{\circ} \mathrm{C}$, stirred an additional one hour then recooled to $-70^{\circ} \mathrm{C}$ prior to the addition of the appropriate acid chloride.

\section{General preparation of $\alpha$-alkyl- $\alpha$-(cyclopropylcarbonyl)acetic acids}

To the prepared solution of Lithium $\alpha$-Lithio carboxylates the acid chloride $(10 \mathrm{mmol})$ was added in $10 \mathrm{~mL}$ of dry THF at $-70^{\circ} \mathrm{C}$ and the mixture was stirred an additional 30 minutes. The reaction mixture was added to $20 \mathrm{~mL}$ of $2 \mathrm{M} \mathrm{HCl},(40 \mathrm{mmol})$, and $50 \mathrm{~g}$ of ice. The cloudy solution was washed three times with $30 \mathrm{~mL}$ of $\mathrm{CH}_{2} \mathrm{Cl}_{2}$. The combined organic layers were dried over $\mathrm{MgSO}_{4}$, filtered and the solvent evaporated under reduced pressure. All operations were kept at $0^{\circ} \mathrm{C}$. Upon triturating with cold pentane crystalline $\alpha$-(cyclopropylcarbonyl)- $\alpha$-alkyl acetic acids were obtained.

$\alpha$-(Cyclopropylcarbonyl)- $\alpha, \alpha$-dimethyl propionic acid. The crude solid, $1.04 \mathrm{~g}$, (67\%), was recrystallized from a $2: 1$ pentane-ether to yield $0.91 \mathrm{~g},(54 \%)$ of a solid $\left(\mathrm{mp} 68-71^{\circ} \mathrm{C}\right) . \mathrm{IR}\left(\mathrm{CCl}_{4}\right)$ 3400-2450, (br), 1698, 1435, 1245, 1155, $930 \mathrm{~cm}^{-1} ;{ }^{1} \mathrm{H}$ NMR $\left(\mathrm{CDCl}_{3}\right) \delta 10.3-10.0$ (br, $\left.1 \mathrm{H}\right), 2.8$ $(\mathrm{m}, 1 \mathrm{H}), 1.31(\mathrm{~s}, 6 \mathrm{H}), 1.1-0.7(\mathrm{~m}, 4 \mathrm{H})$. Elemental Analysis, Calculated for $\mathrm{C}_{8} \mathrm{H}_{12} \mathrm{O}_{3}$ : C 61.53; H, 7.69. Found: C, 62.12; H, 7.53.

$\alpha$-(Cyclopropylcarbonyl)cyclobutanecarboxylic acid. The crude solid, $0.85 \mathrm{~g}$, (51\%), was recrystallized from a 2:1 pentane-ether to yield $0.52 \mathrm{~g}$, $(31 \%)$ of an intractable oil $\left(\mathrm{dec}\left(-\mathrm{CO}_{2}\right)\right.$ $\left.>85^{\circ} \mathrm{C}\right)$. IR $\left(\mathrm{CCl}_{4}\right) 3450-2400$, (br), 1680, 1425, 1230, 1130, $950 \mathrm{~cm}^{-1} ;{ }^{1} \mathrm{H} \mathrm{NMR}\left(\mathrm{CDCl}_{3}\right) \delta 10.1-$ 9.9 (br, $1 \mathrm{H}), 3.0-1.5(\mathrm{~m}, 7 \mathrm{H}), 1.1-0.7(\mathrm{~m}, 4 \mathrm{H})$. Elemental Analysis, Calculated for $\mathrm{C}_{9} \mathrm{H}_{12} \mathrm{O}_{3}$ : C 64.28; H, 7.14. Found: C, 64.57; H, 7.22.

$\alpha$-(Cyclopropylcarbonyl)- $\alpha$-methyl propionic acid. The crude solid, $1.04 \mathrm{~g}$, (67\%), was recrystallized from a $2: 1$ pentane-ether to yield $0.91 \mathrm{~g},(54 \%)$ of a solid $\left(\mathrm{mp} 68-71^{\circ} \mathrm{C}\right) . \mathrm{IR}\left(\mathrm{CCl}_{4}\right)$ 3450-2400, (br), 1695, 1440, 1270, 1240, 1155, 1035, $930 \mathrm{~cm}^{-1} ;{ }^{1} \mathrm{H}$ NMR $\left(\mathrm{CDCl}_{3}\right) \delta 10.2-10.0$ (br, 1H), $3.4(\mathrm{q}, 1 \mathrm{H}), 2.6(\mathrm{~m}, 1 \mathrm{H}), 1.26(\mathrm{~s}, 3 \mathrm{H}), 1.1-0.7(\mathrm{~m}, 4 \mathrm{H})$. Elemental Analysis, Calculated for $\mathrm{C}_{7} \mathrm{H}_{10} \mathrm{O}_{3}$ : C 59.15; H, 7.04. Found: C, 59.74; H, 7.31.

General procedure for the synthesis of allyl ketones ${ }^{13 \mathrm{a}}$

Aluminum Chloride, (4.0 mmol), was added at once to a solution of zinc powder, (40.0 mmol), The appropriate nitrile, $(10.0 \mathrm{mmol})$, and allylic bromide, $(15.0 \mathrm{mmol})$ in $50 \mathrm{~mL}$ of anhydrous 
THF at $0^{\circ} \mathrm{C}$ in an ice bath. The reaction was allowed to warm to room temperature and stirred an additional 2.5 hours. [The course of the reaction was monitored by TLC using silica gel with a fluorescent indicator and using isopropanol as the developing agent.] The work up consisted of quenching the reaction with $50 \mathrm{~mL}$ of $2 \mathrm{M}$ aqueous $\mathrm{HCl}$ and stirring for an addition 5 minutes. The mixture was passed through a short silica gel column to remove inorganics, and the organic solvent was removed by rotoevaporation. [It should be noted that using nitriles smaller than valeronitrile led to allyl ketone that were difficult to isolate due to their volatility.] Further purification was accomplished using flash chromatography with ethyl acetate/hexane as the eleuent.

1-Cyclopropyl-3-buten-1-one. The crude oil was distilled in vacuo at $25 \mathrm{mmHg}^{-1}$ [bath temperature $\left.65^{\circ} \mathrm{C}\right]$ yielding $0.70 \mathrm{~g},(64 \%)$, of a clear oil. IR $\left(\mathrm{CCl}_{4}\right) 3125,3000-2850(\mathrm{br}), 1715$, 1640, 1440, 1230, $930 \mathrm{~cm}^{-1} ;{ }^{1} \mathrm{H}$ NMR $\left(\mathrm{CDCl}_{3}\right) \delta 5.9$ (pentet, 1H), $5.2(\mathrm{~m}, 2 \mathrm{H}), 3.4(\mathrm{~d}, 2 \mathrm{H}), 2.2$ $(\mathrm{m}, 1 \mathrm{H}), 1.1-0.7(\mathrm{~m}, 4 \mathrm{H})$. Elemental Analysis, Calculated for $\mathrm{C}_{7} \mathrm{H}_{10} \mathrm{O}: \mathrm{C} 76.36 ; \mathrm{H}, 9.09$. Found: C, 76.53; H, 8.67.

1-Phenyl-3-buten-1-one. The crude oil was distilled in vacuo at $25 \mathrm{mmHg}^{-1}$ [bath temperature $\left.83^{\circ} \mathrm{C}\right]$ yielding $1.18 \mathrm{~g},(81 \%)$, of a clear oil. IR $\left(\mathrm{CCl}_{4}\right)$ 3100-3025, 2980-2850, 1695, 1600, 1450, 1200, 750, $700 \mathrm{~cm}^{-1} ;{ }^{1} \mathrm{H} \mathrm{NMR}\left(\mathrm{CDCl}_{3}\right) \delta 8.1(\mathrm{~d}, 2 \mathrm{H}), 7.5(\mathrm{~m}, 3 \mathrm{H}), 6.0-5.5(\mathrm{~m}, 1 \mathrm{H})$, 5.1-5.0 (m, $2 \mathrm{H}), 2.9(\mathrm{~m}, 2 \mathrm{H})$. Elemental Analysis, Calculated for $\mathrm{C}_{10} \mathrm{H}_{10} \mathrm{O}: \mathrm{C} 82.19 ; \mathrm{H}, 6.85$. Found: C, 81.78; H, 7.08.

1-Butyl-3-buten-1-one. The crude oil was distilled in vacuo at $25 \mathrm{mmHg}^{-1}$ [bath temperature $55^{\circ} \mathrm{C}$ ] yielding $0.64 \mathrm{~g},(51 \%)$, of a clear oil. IR $\left(\mathrm{CCl}_{4}\right)$ 3100-3025, 2980-2850, 1710, 1610, 1430, 1245, 950, $\mathrm{cm}^{-1} ;{ }^{1} \mathrm{H}$ NMR $\left(\mathrm{CDCl}_{3}\right) \delta 8.1(\mathrm{~d}, 2 \mathrm{H}), 7.5(\mathrm{~m}, 3 \mathrm{H}), 5.6(\mathrm{~m}, 1 \mathrm{H}), 5.1(\mathrm{~m}, 2 \mathrm{H}), 3.2(\mathrm{~m}$, 2H), $2.9(\mathrm{t}, 2 \mathrm{H}), 1.7$, (pentet, $2 \mathrm{H}), 1.4$ (sextet, 2H), 0.9 (t, 3H). Elemental Analysis, Calculated for $\mathrm{C}_{8} \mathrm{H}_{14} \mathrm{O}$ : C 76.19; $\mathrm{H}, 11.11$. Found: C, 76.58; H, 11.43 .

\section{General procedure for the synthesis of $\alpha$-(carbonyl)-3-butenoic acids ${ }^{14 b}$}

The dianion of 3-butenoic acid was prepared as described above with the exception of the addition of 1.2 equivalence of HMPT prior to the addition of the 3-butenoic acid. The reaction was stirred an additional hour at $-78^{\circ} \mathrm{C}$ then the desired acid chloride, ( 1 equivalence in anhydrous THF) was added slowly keeping the temperature below $-60^{\circ} \mathrm{C}$. The work up consisted of adding $5 \% \mathrm{HCl}$ to the mixture not letting the temperature rise above $10^{\circ} \mathrm{C}$, separating the organic phase, washing, cold with $5 \% \mathrm{HCl}$ and the water. The organic phase was dried over $\mathrm{MgSO}_{4}$ and rotoevaporated. The crude oil was induced to solidification with pentane and recrystallized from pentane.

$\alpha$-(Cyclopropylcarbonyl)-3-butenioc acid. A melting point for the product, 0.83g, (54\%), could not be obtained due to decomposition. IR ( $\left.\mathrm{CCl}_{4}\right)$ 3600-2500 (br), 1715, 1690, 1625, 1360, 1210, 1160, 1145, $730 \mathrm{~cm}^{-1} ;{ }^{1} \mathrm{H}$ NMR $\left(\mathrm{CDCl}_{3}\right) \delta 12.1$ (broad, $\left.1 \mathrm{H}\right), 5.7(\mathrm{~m}, 1 \mathrm{H}), 5.4(\mathrm{~d}, 1 \mathrm{H}), 5.1$ $4.9(\mathrm{~m}, 2 \mathrm{H}), 2.2(\mathrm{~m}, 1 \mathrm{H}), 1.1-0.7(\mathrm{~m}, 4 \mathrm{H})$. Elemental Analysis, Calculated for $\mathrm{C}_{8} \mathrm{H}_{10} \mathrm{O}_{3}$ : C 62.33; H, 6.67. Found: C, 62.84; H, 7.06.

$\alpha$-(Phenylcarbonyl)-3-butenioc acid. The reprecipitated product yielded, $1.14 \mathrm{~g},(60 \%)$, however the melting point could not be obtained due to decomposition. IR $\left(\mathrm{CCl}_{4}\right)$ 3600-2500 
(br), 1725, 1695, 1620, 1385, 1215, 1170, $830 \mathrm{~cm}^{-1} ;{ }^{1} \mathrm{H}$ NMR $\left(\mathrm{CDCl}_{3}\right) \delta 12.0$ (broad, $\left.1 \mathrm{H}\right), 8.0$ (d, 2H), $7.4(\mathrm{~m}, 3 \mathrm{H}), 5.6(\mathrm{~m}, 1 \mathrm{H}), 5.3(\mathrm{~d}, 1 \mathrm{H}), 5.1-4.9(\mathrm{~m}, 2 \mathrm{H})$. Elemental Analysis, Calculated for $\mathrm{C}_{11} \mathrm{H}_{10} \mathrm{O}_{3}$ : C 69.47; H, 5.26. Found: C, 69.94; H, 5.18.

$\alpha$-(Methylcarbonyl)-3-butenioc acid. The reprecipitated product yielded, $0.54 \mathrm{~g},(42 \%)$, however the melting point could not be obtained due to decomposition. IR $\left(\mathrm{CCl}_{4}\right)$ 3600-2500 (br), 1710, 1685, 1615, 1405, 1235, 1185, 1120, 935, $830 \mathrm{~cm}^{-1} ;{ }^{1} \mathrm{H}$ NMR $\left(\mathrm{CDCl}_{3}\right) \delta 12.0$ (broad, $1 \mathrm{H}), 5.6(\mathrm{~m}, 1 \mathrm{H}), 5.3(\mathrm{~d}, 1 \mathrm{H}), 5.1-4.9(\mathrm{~m}, 2 \mathrm{H}), 2.2(\mathrm{~s}, 3 \mathrm{H})$. Elemental Analysis, Calculated for $\mathrm{C}_{11} \mathrm{H}_{10} \mathrm{O}_{3}$ : C 56.25; $\mathrm{H}, 6.25$. Found: C, 55.72; $\mathrm{H}, 6.67$.

\section{General procedure for the synthesis of 2-substituted-4,5-dihydrofurans}

The decarboxylative rearrangements were attempted on each of the above structures. Samples were placed in low-pressure reaction tubes and all were heated to $120^{\circ} \mathrm{C}$ in a preheated oil bath for 45 minutes. In the cases of the a-(carbonyl)cyclopropane carboxylic acids and the a(carbonyl)-3-butenoic acids, loss of $\mathrm{CO}_{2}$ ceased after about 10 minutes and the products were examined and found to be the 2-substituted-4,5-dihydrofurans. In the case of the $\alpha$-alkyl- $\alpha$ (cyclopropylcarbonyl)acetic acids, gas evolution ceased after approximately 30 minutes, and the only isolated products were the ketones. None of the other compounds showed any evolution of gas and only starting material was recovered.

2-Cyclopropyl-4,5-dihydrofuran. The yield was greater than 90\%. Crude product showed no indication of starting material or dicyclopropyl ketone in the residual oil. IR (neat) 3020, 2990, 1450, 1400, 1320, $1075 \mathrm{~cm}^{-1} .{ }^{1} \mathrm{H}$ NMR $\delta 4.26(\mathrm{t}, 1 \mathrm{H}), 2.65(\mathrm{~m}, 2 \mathrm{H}), 2.05(\mathrm{~m}, 2 \mathrm{H}), 1.45(\mathrm{~m}, 1 \mathrm{H})$, 1.0 (m, 4H). Elemental Analysis, Calculated for $\mathrm{C}_{7} \mathrm{H}_{10} \mathrm{O}: \mathrm{C}, 76.36 ; \mathrm{H}, 9.09$. Found: $\mathrm{C}, 75.52 ; \mathrm{H}$, 8.79 .

2-Phenyl-4,5-dihydrofuran. The yield was greater than 90\%. Crude product showed no indication of starting material and a 7\% yield [GC] of Phenyl cyclopropyl ketone in the residual oil. Distillation gave a pure product. IR (neat) 3100-2890, 1445, 1420, 1375, 1315, $1075 \mathrm{~cm}^{-1}$. ${ }^{1} \mathrm{H}$ NMR $\delta 7.32(\mathrm{~m}, 5 \mathrm{H}), 4.28(\mathrm{t}, 1 \mathrm{H}), 2.51(\mathrm{~m}, 2 \mathrm{H}), 1.96(\mathrm{~m}, 2 \mathrm{H}) . \quad$ Elemental Analysis, Calculated for $\mathrm{C}_{10} \mathrm{H}_{10} \mathrm{O}: \mathrm{C}, 82.19 ; \mathrm{H}, 6.85$. Found: $\mathrm{C}, 81.88 ; \mathrm{H}, 6.59$.

2-Methyl-4,5-dihydrofuran. The yield was greater than $90 \%$. Crude product showed no indication of starting material or methyl cyclopropyl ketone in the residual oil. IR (neat) 3120 , 2820, 1445, 14150, 1310, $1075 \mathrm{~cm}^{-1} .{ }^{1} \mathrm{H}$ NMR $\delta 4.24(\mathrm{t}, 1 \mathrm{H}), 2.57$ (m, 2H), 2.08 (m, 2H), 1.23 (s, 3H). Elemental Analysis, Calculated for $\mathrm{C}_{5} \mathrm{H}_{8} \mathrm{O}: \mathrm{C}, 71.42 ; \mathrm{H}, 9.52$. Found: C, 71.06; H, 8.79.

\section{Acknowledgements}

This work was stimulated by Professor Berhanu Abegaz. Throughout my entire career, [EJ], he has been a consummate colleague. His research is of the highest caliber, his teaching is something I would strive to emulate and his friendship is something I cherish. My students, through my professional and personal friendship with Prof. Abegaz, have benefited from his 
life's work and are in many ways his intellectual nieces and nephews. It is privilege and an honor to acknowledge his contribution and dedicate this paper to him.

\section{References}

1. Jahngen, E. G. E.; Phillips, D., Kobelski, R. J., Demko, D. M. J. Org. Chem. 1983, 48, 2472.

2. Simpson, J. M., Richey, H. G., Jr. Tetrahedron Letts. 1973, 27,2545.

3. Alonso, M. E., Morales, A. J. Org. Chem. 1980, 45, 4530.

4. Ranu, B. C., Banerjee, S., Das, A. Tetrahedron Letts. 2006, 47, 881.

5. (a) Pittman, C. U., Jr., McManus, S. P. J. Am. Chem. Soc. 1969, 91, 5915. (b) Ford, W. T., Newcomb, M. J. Am. Chem. Soc. 1973, 95, 6277.

6. (a) Dolbier, W. R., Jr., Sellers, S. F. J. Org. Chem. 1982, 47, 1. (b) Danheiser, R. L., Martinez-Davila, C, Morin, J. M. J. Org. Chem. 1980, 45, 1340. (c)McGreer, D. E., McKinley, J. W. Can. J. Chem. 1973, 51, 1487.

7. (a) Oxgaard, J, Wiest, O, Eur. J. Org. Chem. 2003, 8, 1454. (b) Bigley, D. B., Thurman, J. C. Tetrahedron Letts. 1967, 25, 2377. (c) Hanafusa, T., Birladeanu, L, Winstein, S. J. Am. Chem. Soc. 1965, 87, 3510.

8. (a) Stevens, R. V., DuPree, L. E., Jr., Lowenstein, P. L. J. Org. Chem. 1972, 87, 977. (b) Pinnick, H. W., Chang, Y-H. Tetrahedron Letts. 1979, 10, 837.

9. Bigley, D. B., Thurman, J. C. Tetrahedron Letts. 1965, 51, 4687.

10. (a) Logue, M. W. J. Org. Chem. 1974, 39, 3455. (b) Krapcho, A. P. K., Kashdan, D. S., Jahngen, E. G. E., Jr, Lovey, A. J. J. Org. Chem. 1977, 42, 1189. (c) Kuo, Y-N., Yahner, J. A., Ainsworth, C. J. Am. Chem. Soc. 1971, 93, 6321.

11. Pinnick, H. W., Chang, Y-H., Foster, S. C., Govindan, M. J. Org. Chem. 1980, 45, 4505.

12. Berkowitz, W. F., Ozorio, A. A. J. Org. Chem. 1971, 36, 3787. (b) Berkowitz, W. F. J. Org. Chem. 1972, 37, 341.

13. (a) Lee, A. S-Y., Lin, L-S. Tetrahedron Letts. 2000, 41, 8803. (b) Ragoussis, V, Giannikopoulos, A. Tetrahedron Letts. 2006, 47, 683.

14. (a) Pfeffer, P. E., Silbert, L. S. J. Org. Chem. 1971, 36, 3290. (b) v. d. Veen, R. H., Cerfontain, H. J. Org. Chem. 1985, 50, 342.

15. (a) Huisgen, R., Otto, P. J. Am. Chem. Soc. 1968, 90, 5342. (b) Huisgen, R., Steiner, G. J. Am. Chem. Soc. 1973, 95, 5054.

16. Snyder, L. R., Kirkland, J. J.,Glajch, J. L. In Introduction to Modern Liquid Chromatography, Wiley-Interscience: New York, 1997, Appendix II, pp.722-723. 